\title{
Gentrificação da cidade modernista: Brasília
}

\author{
Gentrification of the modernistic \\ city: Brasília
}

William Lauriano

\section{Resumo}

Este artigo procura a ocorrência da gentrificação em Brasília. Há críticas em relação aos custos econômicos e sociais, relativo aos efeitos da arquitetura panóptica na sociedade, e, principalmente, o papel e grau de intervenção do Estado presentes na alta carga de regulação urbanística e no monopólio do mercado fundiário, restringindo a oferta habitacional, resultando num padrão de ocupação territorial enquadrada no modelo de cidade COM-FUSA, compactas e difusas no território. A gentrificação generalizada é percebida na afirmação de que Brasília é a cidade do automóvel, observada pela maior proporção de automóveis por habitantes, mas principalmente devido à quantidade de carros para uso na roça, CAR-ROÇAS. Constata-se que o problema do déficit habitacional não é de escassez de solo, é de propriedade.

Palavras-chave: gentrificação; Brasília; mercado imobiliário; capacidade institucional; bolha imobiliária; cidade COM-FUSA; arquitetura panóptica; consumo de automóveis; déficit habitacional.

\begin{abstract}
This article investigates the occurrence of gentrification in Brasilia. There is criticism in relation to economic and social costs, to the effects of panoptic architecture in society, and especially to the State's role and level of intervention, present in the high degree of urban regulation and in the monopoly of the land market. All these factors restrict the housing supply, and result in a pattern of territorial occupation framed in the city model called COM-FUSA (CON-FUSED), compact and diffused in the territory. Widespread gentrification is perceived in the statement that Brasilia is the automobile city, which is revealed by the largest proportion of cars per inhabitants, and mainly by the amount of cars for use in the fields. It is observed that the housing deficit problem is not related to land scarcity, but to property scarcity.
\end{abstract}

Keywords: gentrification; Brasília; housing market; institutional capacity; housing bubble; CON-FUSED city; panoptic architecture; automobile consumption; housing deficit. 


\section{Introdução}

As políticas públicas de planejamento urbano apresentam um descompasso entre a teoria do urbanismo, o discurso dos planejamentos estratégicos e a realidade brasileira. Há um descolamento entre a realidade social e espacial e a legislação urbana, os discursos, o planejamento e a regulação urbanística (Arantes, 2000). Evidente pelo expressivo crescimento da ocupação ilegal, não apenas por favelas, mas também por condomínios de luxo. $\mathrm{Na}$ cidade ilegal, no lugar fora das ideias não há planos, nem ordem, mal se conhece em suas dimensões e características. A ilegalidade é funcional, permite as relações clientelistas, políticas arcaicas, um mercado imobiliário restrito e especulativo, com aplicação arbitrária da lei. Para uns, a ocupação é considerada ilegal, para outros, irregular.

0 planejamento urbano modernista, funcional, apoiado na centralização e na racionalidade do Estado, foi aplicado apenas a uma parte das cidades, em sua parte formal ou legal. Vale para muitas cidades, mas principalmente em Brasília; a importação dos padrões urbanísticos aplicados apenas a uma parte da cidade contribuiu para uma modernização incompleta e excludente.

0 modelo brasiliense de cidade formal modernista impõe um conjunto de requisitos normativos que se erguem como uma barreira institucional para a provisão de habitações para os setores populares da sociedade, induzindo esses a buscar alternativas irregulares.

Com um mercado formal orientado a atender apenas parte da sociedade, os de maior renda. Os demais buscam alternativas no mercado informal para enfrentar a falta de moradia. A representação espacial da interação entre os mercados formal e informal do solo urbano aparece na forma compacta e difusa das metrópoles brasileiras. Ocupações compactas multipolarizadas, difusas no território. Em Brasília, esta forma COM-FUSA, simultaneamente compacta e difusa, é mais intensa.

\section{Plano-Piloto de gentrificação}

Qual o estado atual da condição urbana? Será que ocorre um amplo processo de enobrecimento urbano? Um plano nacional de enobrecimento? Houve em Brasília intenção (explícita ou oculta) de enobrecimento?

Extrapolando alguns cuidados, é possível pensar em uma identidade entre: urbanizar, gentrificar, enobrecer, aburguesar, desenvolver? Ao afirmar que Brasília é uma cidade modernista, também que se inspira na industrialização. Mas onde está a fábrica? Não uma só, mas o conjunto. Trata-se do que inspirava as ideias de Niemeyer, Lúcio Costa e JK. 0 moderno produzido pela indústria.

São grandes questões, praticamente impossíveis de encontrar uma resposta. Fazem parte da inspiração...

Um dos princípios de urbanizar é promover o desenvolvimento de uma localidade. Sendo o mercado fundiário um dos principais componentes da urbanização. Considerando que a parte formal do mercado fundiário brasileiro atinge menos da metade da população, e é direcionado para estratos de renda mais elevada, pode-se encontrar uma estreita relação entre urbanizar e enobrecer. Gentrificar. 
Nunca faltaram elogios e reconhecimento a Brasília, principalmente ao valor arquitetônico e estético. No entanto, há também muitas críticas negativas, nada escapa: a decisão de fazer pouco democrática, a pouca transparência, o modo e pressa de entregar a obra, o modelo urbano, os custos e também a arquitetura. Para Celso Furtado, Brasília nunca foi discutida profundamente, e quem questiona arrisca-se a ser satanizado, porque avaliar Brasília equivale a falar mal do Brasil (Couto, p. 219). A opinião de Furtado (apud Couto, p. 220) em dezembro de 1999 era de que:

A interiorização tem aspectos positivos. A construção de estradas e tudo isso que se fez em torno da ocupação do Brasil. 0 país tem uma fronteira aberta imensa. Foi positivo. 0 erro foi não discutir a coisa seriamente. Não ir para a mesa e perguntar: "Como vamos pagar isso? Vamos ver se isso não distorce demasiado os investimentos. Vamos ver se o Brasil pode sustentar isso. Que consequências terá?" (...) Há muita coisa a se discutir no caso de Brasília. Mas até hoje não se vê ninguém falar nisso, porque é como se fosse contra o Brasil. (Couto, p. 220)

Gilberto de Melo Freyre avaliava nos anos 1960 que o erro foi "essa construção se processar como pura obra da arquitetura e engenharia" (Freyre, 1968, p. 19), o imenso erro praticado foi "o de fazer uma pura cidade teatral" (ibid., p. 192). Para ele esqueceu-se de toda uma "experiência feita" que os arquitetos desprezaram "em favor do efeito cenográfico que imaginam estético" (ibid., p. 196). "Faltou uma equipe interdisciplinar, com a contribuição de cientistas sociais, e outros especialistas" (ibid., p. 256). Aponta problemas em relação ao aspecto psicológico das construções, temendo que Brasília se torna uma cidade kafkiana, burocraticamente mecanizada. A cidade sofria com a "planificação de rigor militar para uma democracia" (ibid., p. 261), entendia que a cidade estava mais voltada para a estética que para a vida. Trinta anos depois da construção Freyre (in Correio Braziliense, 1980, p. 17) ainda tinha duras críticas:

A maneira como Brasília foi feita, sob uma perspectiva do assunto inteiramente ditatorial, não foi nada boa. Fala-se muito hoje (1980), em governos militares ditatoriais no Brasil nesses últimos anos. Quem foi mais ditatorial no Brasil que Juscelino, no modo de criar Brasília? Ele agiu como um faraó: chamou dois arquitetos, aliás ilustres, e disse: vocês vão levantar uma capital e eu dou carta branca a vocês. (...) 0 que era necessário era convocar geógrafos, ecologistas, cientistas sociais, educadores, artistas, para darem opinião sobre a futura capital. Não se fez isso. Erros tremendos foram cometidos (...). Por exemplo, espaços para o lazer, para recreação, para grandes ajuntamentos dentro da cidade, (...). Nada disso se fez. Foi preciso fazer isso depois, já com muita dificuldade, porque já tinha se dado a exploração imobiliária dos espaços de Brasilia. Realmente, Brasília habitada está sendo humanizada pelos seus habitantes, mas ela começou inumana.

Um dos integrantes da equipe que formulou o Plano de Metas do governo Kubitschek, Roberto Campos, considerava Brasília incestuosa, incrustada de guetos, onde políticos falam com políticos, burocratas com burocratas, isto é, lugar em que a miscigenação social é escassa e onde o povo está fora, nas cidades satélites, em dezembro de 1999 ainda não estava conformado, dizendo que: 
As consequências de Brasília foram mais negativas do que positivas. Primeiro foi um fator enorme de inflação, com investimento improdutivo na burocracia. E que se tornou ainda mais caro pela pressa de Juscelino na construção. Ele queria tornar a construção de Brasília irreversível e por isso fixou para si mesmo a meta de quatro anos. (...) Um efeito negativo é que Brasília poderia ter sido usada para a descentralização burocrática e não o foi. (...) Outro efeito negativo foi a corrupção moral. Os funcionários tiveram que ser "peitados" para ir para Brasília. 0 atrativo era a "dobradinha", o duplo salário. Quando cessou a condição pioneira, a dobradinha foi substituída por vantagens especiais de transporte e habitação subvencionados. Mas continuou o problema. (...) em Brasília a falta de atividade econômica fez com que se começasse a intensificar o uso da propina como salário suplementar. A resistência ética à propina foi consideravelmente reduzida, exatamente porque funcionários começaram a considerar aquilo como uma espécie de suplemento do salário inadequado. (Apud Couto, p. 219)

As críticas negativas em relação aos custos da burocracia e aspectos morais do corporativismo estatal também eram feitas por Mário Henrique Simonsen em 1995, Ministro da Fazenda no governo Geisel e do Planejamento no início do governo Figueiredo:

Eu acho que o maior problema é que ela acabou sendo uma cidade pura e simplesmente burocrática. E é uma cidade cujo layout isola as pessoas em guetos. Os deputados moram nos blocos de deputados. Os senadores, nos blocos de senadores. Todos cercados de funcionários públicos por todos os lados. Então, o clima de Brasília é um clima corporativista. (Apud Couto, p. 221)
Com o mesmo tipo de preocupação, em março de 2000, Delfim Netto considerava: "Brasília virou uma corte. É uma sociedade endogâmica, que casa entre si os seus filhos. Vai ser muito difícil arejá-la, porque todo mundo é parente. (...) Aquilo é inabitável. Mas quem mora ali é obrigado a ficar. Na verdade, é uma escultura. Então você mora dentro de uma escultura" (apud Couto, p. 223). Apesar de não ser unânime o reconhecimento da beleza arquitetônica, todos condenam a funcionalidade das obras. Critica-se a adaptação ao clima da região, a organicidade no uso do espaço. Aponta-se o privilégio da forma em detrimento da funcionalidade e do conforto ambiental. A obra é boa para se morar em frente, dentro não.

0 conceito da gentrificação clássica inicialmente utilizada para descrever a ocorrência do fenômeno em bairros industriais não se aplica a Brasília; nessa cidade cabe a noção da gentrificação generalizada, a que transpassa do setor imobiliário e atinge outros âmbitos (cultural, consumo, econômico, etc.) (Smith, 2006). A gentrificação generalizada pode ser entendida a partir de algumas características interligadas, o que não significa que todas devem estar presentes: o novo papel do Estado, a participação do capital financeiro, as mudanças nos níveis de oposição política e enfrentamento ao processo, a dispersão geográfica e, por fim, a gentrificação setorial, essa última entendida como a extensão dos efeitos do processo sobre as atividades de trabalho, lazer e consumo (Smith, 2007, p. 25).

Para compreender o uso do solo urbano é fundamental analisar o mercado imobiliário (Abramo, 2001; Farret, 2001). Por isso é imperioso entender como isso ocorre, quais suas características e resultados, observando quais 
foram as consequências do Plano-Piloto para o mercado de terras do Distrito Federal e influências nas Cidades do Entorno.

Considerando o rápido crescimento populacional, pode-se dizer no mínimo que Brasília proporcionou parcelamento de algumas cidades que já existiam na região e nascimento de outras Cidades do Entorno, formando o subúrbio brasiliense.

A ampliação da rede de transporte convergindo para Brasília causou e intensificou um fluxo de migrantes criando dificuldades para alocar todos. 0 hiato entre o crescimento da Capital em relação à economia da região periférica contribuiu para aumentar os desequilíbrios inter-regionais.

Mas por que fazer Brasília? A decisão foi complexa e anunciada de última hora, pois, de fato, não integrava as diretrizes iniciais ditadas por Juscelino à equipe responsável pelo Plano de Metas. Teve de ser feita a partir de uma meta especial, uma meta-síntese, apresentada depois do planejamento geral do governo JK (Couto, 2002, p. 195).

Para alguns autores, a construção da nova capital seria a concretização de uma política territorial específica, resultando em uma forma de "harmonizar o complexo jogo de interação entre a economia e a política de uma determinada formação social e histórica. Nasce da concretização num momento histórico em que o país se encontrava em rápido desenvolvimento capitalista, quando era necessário expandir o mercado nacional e colonizar o centro-norte do país, que ainda era selvagem (Farret, 1985, pp. 19-23).

0 projeto vencedor do concurso, do Lúcio Costa, conforma o Plano-Piloto a partir do sinal da cruz. Em forma de avião ou pássaro de asas abertas. "Nasceu do gesto primário de quem assinala um lugar ou dele toma posse: dois eixos cruzando-se em ângulo reto, ou seja, o próprio sinal da cruz". Ao que parece, a intensão era muito mais a segunda, tomar posse:

(...) a concepção urbanística da cidade propriamente dita, porque esta não será, no caso, uma decorrência do planejamento regional, mas a causa dele: sua fundação é que dará ensejo ao ulterior desenvolvimento planejado da região. Trata-se de ato desbravador, nos moldes da tradição colonial. E o que se indaga é como no entender de cada concorrente uma tal cidade deve ser concebida. (...) Ela deve ser concebida não como simples organismo capaz de preencher satisfatoriamente, sem qualquer esforço, as funções vitais próprias de uma cidade moderna qualquer, não apenas uma urbs, mas como civitas, possuidora dos atributos de uma capital. (...) Cidade planejada para o trabalho ordenado e eficiente, mas ao mesmo tempo cidade viva e aprazível, própria ao devaneio e à especulação intelectual, capaz de tornar-se com o tempo, além de centro de governo e administração, num foco de cultura das mais lúcidas do país (fragmentos do memorial apresentado, Lúcio Costa, 1957). (Grifos próprios)

0 plano foi concebido para 500 mil habitantes no final do século. Em 2010, a população do Distrito Federal ultrapassava 2,5 milhões de habitantes, no entanto, no "bairro" Plano Piloto a população ainda se aproximava de 300 mil habitantes (IBGE, Censo 2010). A Capital foi concebida com setores específicos para cada função. Em relação ao problema residencial Lúcio Costa escreveu: 
Quanto ao problema residencial, ocorreu a solução de criarmos uma sequencia contínua de grandes quadras dispostas em ordem dupla ou simples, de ambos os lados da faixa rodoviária, e emolduradas por uma larga cinta densamente arborizada, (...) a fim de resguardar melhor, qualquer que seja a posição do observador, 0 conteúdo das quadras, visto sempre num segundo plano e como que amortecido na paisagem.

[...] A graduação social poderá ser dosada facilmente, atribuindo-se maior valor a determinadas quadras (...). E seja como for, as diferenças de padrão de uma quadra a outra serão neutralizadas pelo próprio agenciamento urbanístico proposto, e não serão de natureza a afetar o conforto social a que todos têm direito. Elas decorrerão apenas de uma maior ou menor densidade, de maior ou menor espaço atribuído a cada indivíduo e a cada família, da escolha dos materiais e do grau de acabamento. Neste sentido, deve-se impedir a enquistação de favelas, tanto na periferia urbana quanto na rural. (Lúcio Costa, 1957, Memorial apresentado)

Originalmente o plano previa construir basicamente três tipos de prédios, visando três faixas de renda diferentes, de modo a propiciar maior integração de camadas sociais por contato, vizinhança e pelo uso comum de escolas, comércio e clubes (Couto, 2002, p. 120). Apesar de ter a ideia de integração entre classes sociais, tem algo de segregador. Não é a diferenciação exclusivamente do projeto que caracteriza a segregação, talvez mais a diferença de qualidade, de padrão, de acesso diferenciado a bens e serviços, equipamentos e oportunidades. Na prática, famílias de classes sociais diferentes foram morar em locais diferentes. Os pobres na periferia. A integração das classes ficou apenas no discurso, no Plano-Piloto de papel. Utopia.

Brasília não tem sido capaz de lidar adequadamente com o crescimento populacional e a rápida urbanização. A estrutura espacial de sua região metropolitana (RM) é consideravelmente distinta de outras regiões. A distinção maior está no mercado de terras.

As políticas restritivas de desenvolvimento territorial resultaram numa forma espraiada, dispersa de ocupação territorial. Há uma periferização, uma relação entre centro e periferia que também ocorre nas demais regiões metropolitanas brasileiras onde há dispersão na ocupação territorial, a cidade COM-FUSA, compacta e difusa (Abramo, 2007). Em Brasília, esse efeito é mais intenso. Em consequência, os custos de vida são mais elevados, afetando com mais intensidade aqueles com menores oportunidade e renda.

Desde a Constituição da República em 1891, havia a determinação de desapropriação de terras que formariam o Distrito Federal. A intenção seria utilizar os recursos da venda da terra para financiar as obras necessárias para a implantação da Capital. Imediatamente após a inauguração da capital, foi aprovada uma legislação ${ }^{1}$ para preservar a configuração original denominada Plano-Piloto, restringindo o crescimento do mercado imobiliário nesta área (Farret, 2001, p. 13).

Ressalte-se que o Governo de Brasília, preocupado com a proliferação de loteamentos ilegais para a população de baixa renda, proibiu subdivisões dos lotes por promotores privados. Outra questão importante a ressaltar foi o reconhecimento da influência que a nova capital teria nos municípios vizinhos. Impondo restrições ao parcelamento das 
propriedades rurais no entorno, com o objetivo de proteger o chamado "cinturão verde" de Brasília, garantindo assim que essas áreas seriam usadas para fornecer alimentos e outros produtos para a Capital Federal. As restrições objetivavam evitar o parcelamento caótico da terra. Como resultado, desde os anos 1980, intensificou-se a ocorrência de assentamentos sem qualquer disposição de infraestrutura, serviços e equipamentos sociais ou empregos (Farret, 2001, p. 14).

Passados quase trinta anos, em 1987, a Unesco reconheceu o conjunto construído em decorrência do plano original como Patrimônio Mundial, tornando-se o primeiro conjunto de monumentos edificados no século $X X$ a receber proteção das Nações Unidas.

0 monopólio da propriedade das terras em poder público é uma ferramenta única que o governo local dispõe para o planejamento urbano. Enquanto em outros municípios brasileiros há a presença maciça do setor privado, o governo de Brasília acumula funções de diversos agentes envolvidos na produção do ambiente construído, atuando como proprietário de terras, planejador, programador, construtor $^{2}$ e, em alguns casos, até mesmo como agente financeiro ${ }^{3}$ e vendedor de bens imobiliários. ${ }^{4}$

A partir da construção da Capital, a venda de lotes foi feita sem uma política espacial urbana que considerasse o uso mais eficiente e socialmente justo. 0 regime da propriedade pública da terra não tem sido capaz de assegurar esses objetivos, inicialmente previstos no planejamento urbanístico da chamada área Plano-Piloto (Farret, 2001, p. 13). Desde os anos 1980, proliferam assentamentos irregulares de baixa renda e até mesmo de classe média no subúrbio de Brasília. A propriedade pública da terra foi confinada a limites estritos, dentro apenas do Plano-Piloto.

Utilizando-se do discurso de proteção da qualidade de vida, o governo optou por uma política de ocupação dispersa de baixa densidade, restringindo intencionalmente a oferta habitacional na área nuclear de Brasília. Por outro lado, ao reduzir a oferta imobiliária, esperava-se que a migração de famílias de baixa renda para Brasília seria desencorajada. Isso gerou uma demanda que levou a um intenso processo de urbanização das cidades no entorno de Brasília. Representando um sério problema de gestão, tanto para os governos da Capital, como de Goiás e Minas Gerais (Farret, 2001, p. 13).

As baixas densidades de ocupação exigem investimentos elevados e contínuos do governo e da comunidade em geral, especialmente para manter a infraestrutura urbana necessária. Esse fato demonstra que a propriedade pública do solo urbano não pode, por si só, garantir padrões mais eficientes de uso da terra (Farret, 2001, p. 14).

A rigidez das restrições ao desenvolvimento urbano da capital gerou perversos efeitos nos padrões de desenvolvimento na distribuição espacial dos habitantes. A elevada carga de regulação urbanística no Plano contribuiu potencialmente para a volatilidade e elevação dos preços sobre uma oferta de terrenos que é restrita. É preciso todo o cuidado com essa interpretação, pois, esse é um dos principais argumentos utilizados pelo mercado imobiliário em defesa da flexibilização das regulações. Não há escassez de espaço, é a restrição devido à alta regulação urbanística que gera essa escassez. 
É redundante dizer que no Plano-Piloto, onde está a maior parte do emprego, reside a população de média e alta renda, e nas Cidades Satélites e Entorno do DF, residem as de menor renda. A população de baixa e média renda é forçada a viver nos arredores de 10 até mais de $70 \mathrm{~km}$ do Plano.

A formação do subúrbio brasiliense não ocorreu como na maioria das outras localidades. Essa comparação é complexa, pois o Distrito Federal tem características que o difere de um estado e de um município. No entanto, pode-se dizer que o subúrbio brasiliense é formado por tudo que não faz parte do projeto do Plano-Piloto, incluindo as áreas suburbanas de alta renda (os Lagos Norte e Sul, Park Way, condomínios, etc.). É composto pelas Regiões Administrativas, também denominadas Cidades Satélites, que não foram criadas objetivando um projeto de desenvolvimento, mas, sim, para acomodar a população indesejada nas cercanias do poder. Atribui-se a afirmação a Israel Pinheiro de que o Plano-Piloto deveria estar livre de estudantes e operários (Bomeny, s. d.). As Cidades Satélites foram criadas para "acomodar" a população indesejada que "invadia" a Capital.

A Capital originalmente projetada como um único núcleo, mesmo antes da inauguração, foi acrescida de novos assentamentos distantes na maioria a $30 \mathrm{~km}$ da área do centro, como no caso de Taguatinga em 1958. A população mais pobre foi removida para fora dos limites da bacia do lago Paranoá. Foi um discurso que se justificava pela preocupação ambiental para a proteção dos mananciais e manter a qualidade de vida. Qualidade de vida de quem? Remoções, inclusive forçadas e violentas, são um dos componentes do processo de gentrificação.
A grande participação do Estado no mercado fundiário impôs restrições que geraram a escassez de terra disponível para habitação, aumentando as pressões por demanda, e por consequência, aumentando os preços, impulsionando o nascimento de novas cidades, as Cidades do Entorno.

As pressões migratórias em consequência da busca por oportunidades e emprego, apoiadas por uma política populista para aumentar a base de eleitores, quando associadas às restrições ao acesso à moradia, provocou a necessidade de a população buscar estratégias locacionais alternativas. Pedro Abramo aponta que a falta de uma política habitacional pública eficiente gera uma necessidade que é solucionada através do mercado informal (Abramo, 2007). E foi através da informalidade e ilegalidade que proliferaram os condomínios de luxo e, também, condomínios para as classes populares. Ocorre a retroalimentação entre os mercados formal e informal, entre o mercado imobiliário do Plano-Piloto e o mercado das demais Cidades Satélites e do Entorno.

O subúrbio brasiliense é composto por ocupações pontuais compactas, mas difusas no território, é um exemplo de cidade COM-FUSA (Abramo, 2007). Não é um subúrbio pobre, como o senso comum espera que todo subúrbio brasileiro seja. Não é ainda um subúrbio diversificado, onde se misturam as diferentes classes sociais. Percebe-se que cada região é relativamente homogênea em relação às classes sociais que ali habitam. Por exemplo, nas regiões administrativas Lago Norte e Sul, Park Way, condomínios, Colorado, Setores de mansões, o novíssimo Noroeste, entre outros voltados às classes de mais alta renda. 
As invasões representavam para os governantes uma quebra nos padrões de habitabilidade, e por isso justificavam a remoção com o objetivo de oferecer melhores condições (Saboia e Sandoval, 2012). Melhores condições para quem? Ao longo dos anos esse discurso se mostrou demagogo e populista, diante da precariedade dos novos assentamentos e da violência na remoção das famílias.

A diversidade entre classes é raridade, mas pode ser encontrada exatamente nas invasões, que ao longo do tempo foram consolidadas. É o caso da Vila Planalto e Vila Telebrasília, dentro do Plano-Piloto, ou no caso das misturas entre condomínios de luxo e populares no Vicente Pires.

\section{Mercado fundiário no Distrito Federal e Entorno}

Brasília sobressai quando comparada a capitais de porte similar, suas particularidades únicas do mercado de terras a tornam um caso especial. A organização espacial e o mercado de terras brasiliense são claramente diferentes das outras regiões brasileiras. 0 mais comum é a população de média e baixa renda que se concentra próxima aos centros de negócios, com um desenvolvimento mais compacto. $\mathrm{Na}$ Capital, a ocupação é mais dispersa tendo como resultado um maior consumo de terras. Os impactos ambientais e para a qualidade de vida da população devido à dispersão e ao maior deslocamento são relevantes. Força a população a percorrer distâncias maiores para 0 trabalho e demais consumos diários da cidade.
Implica também os altos custos para o governo prover infraestrutura, impactando também 0 custo da terra.

Muitas das críticas negativas a Brasília enfocam que não foi alcançada a utopia porque a realidade social e econômica foi ignorada. Isso está refletido no rápido crescimento da ilegalidade nas cidades Satélites e do Entorno. 0 crescimento populacional foi maior que a oferta formal de habitações, forçando a população a buscar soluções ilegais em distâncias cada vez maiores e dispersas.

Nos últimos anos tem crescido exponencialmente a oferta formal de habitações, se espraiando para as regiões periféricas. No entanto, é uma oferta formal distinta, direcionada para as classes de média e alta renda. Em contraste com o déficit habitacional, que é concentrado nas classes populares (Fundação João Pinheiro, 2009).

É possível fazer uma breve avaliação da política do solo urbano em Brasília, observando particularmente os efeitos da propriedade pública do solo, com seus efeitos sobre o mercado formal e informal. Uma política de uso do solo urbano pode ser considerada eficaz quando distribui socialmente os ganhos da valorização imobiliária (Farret, 2001, p. 16) podendo ser analisada em função de alguns indicadores.

A localização é sem dúvida um dos principais componentes do custo habitacional. De acordo com evidências em outras cidades, a variação nos preços das habitações está associada a diferentes fatores, mas principalmente à sua localização em relação ao centro, a provisão adequada de infraestrutura e à segurança jurídica quanto à propriedade da terra (Abramo, 2001). 
Umas das formas de avaliar os efeitos da política fundiária é analisar o grau de compactação da área urbanizada. Partindo do pressuposto de que uma ocupação compacta é mais eficiente (ao menos em custos) comparada a uma ocupação dispersa, o crescimento da ocupação urbana na RM brasiliense é acima da média quando comparado a outras RMs. 0 processo de ocupação da Capital foi caracterizado por uma lógica de especulação, em que primeiramente foram urbanizadas e colocadas à venda as áreas mais acessíveis, para depois as menos acessíveis (Farret, 2001, p. 16). 0 resultado dessa política, além de deixar grandes vazios urbanos, contribuiu para distorções na oferta de habitações.

A RM brasiliense tem densidade populacional considerada baixa em relação a suas dimensões e também comparada a outras RMs (Dowall e Monkkonen, 2007). Alterações na densidade de ocupação têm origem desde a construção de Brasília quando Israel Pinheiro alterou o Plano-Piloto original de Lúcio Costa, diminuindo a quantidade de blocos por quadra e ainda aumentando o tamanho dos apartamentos (Carpintero, 2010, p. 348).

Um crescimento maior da população em relação à oferta de imóveis provocará a escassez e, portanto, o aumento dos custos. Cabe frisar a diferença entre o crescimento da oferta de habitações formais e informais. 0 rápido crescimento da participação da produção de habitações informais evidencia o descompasso entre as políticas habitacionais e de infraestrutura e a demanda habitacional. A oferta formal refere-se a áreas legalizadas onde há claramente o direito de propriedade definido, seguindo as regulações e padrões legais. As habitações informais, por outro lado, referem-se às habitações que não seguem os padrões e regulações legais e frequentemente estão localizadas em loteamentos e parcelamentos ilegais sem o mínimo de segurança jurídica da propriedade.

A participação da oferta de habitações informais na capital federal cresceu de 1,6\% em 1991 para 8,2\% em 2000, um crescimento de $25 \%$, enquanto em Curitiba, por exemplo, 0 estoque de habitações informais cresceu apenas 4\% (Dowall e Monkkonen, 2007).

A população brasiliense está concentrada fora do Plano-Piloto, além de $15 \mathrm{~km}$ do centro, contrastando, por exemplo, com Curitiba e Recife, cidades que apresentam o mesmo padrão da maioria das cidades ao redor do mundo, onde a população costuma estar concentrada no centro da cidade e decai a densidade de ocupação afastando-se do centro. Nos primeiros 5 $\mathrm{km}$ a partir do centro, geralmente a densidade é um pouco menor devido ao maior uso para fins comerciais e outros não residenciais.

No entanto, o que se deve destacar é que nos dois exemplos comparativos, no ano de 2000 , mais de $70 \%$ da população vivia dentro de um raio de $15 \mathrm{~km}$ do centro da cidade, enquanto em Brasília menos de 15\% da população (Dowall e Monkkonen, 2007).

0 crescimento populacional também apresenta padrão distinto. Noutras localidades normalmente o crescimento da população, devido entre outros fatores à saturação, tende a diminuir a densidade no centro da cidade, enquanto aumenta a densidade entre 10 e 15 km do centro. É o caso de Curitiba e Recife que, entre os anos 1991 e 2000, diminuiram a participação percentual da população no centro da cidade. Em contraposição, em Brasília mais da metade do crescimento populacional ocorreu 
em áreas a mais de $25 \mathrm{~km}$ do centro (Dowall e Monkkonen, 2007).

0 padrão descentralizado e disperso de crescimento da ocupação urbana em Brasília sugere que as restrições urbanísticas e a propriedade pública do solo urbano provocam distorções profundas no mercado fundiário. Considerando que o crescimento é impedido nas áreas adjacentes ao centro da cidade, o crescimento das áreas para habitação ocorreu em regiões cada vez mais distantes, emergindo uma ocupação territorial não convencional. Um problema a ser destacado é que, enquanto a moradia se distancia do Plano-Piloto, o emprego formal continua concentrado nesta área.

A área ocupada e urbanizada também apresenta diferenças marcantes em Brasília. Na área nuclear, entre $5 \mathrm{~km}$ do centro, devido às restrições, a área ocupada por edificações não chega a $10 \%$, enquanto em Curitiba chega a 90\%. 0 mesmo contraste é percebido nas outras áreas da cidade ao constatar que cerca de $45 \%$ da terra urbanizada está a mais de 20 $\mathrm{km}$ do centro. Muito, quando comparado a Recife e Curitiba onde a distância da terra urbanizada é de aproximadamente 25\% (Dowall e Monkkonen, 2007).

A distribuição espacial entre habitações formais e informais também é diferenciada. Em cidades onde o mercado de habitação é competitivo, com vários ofertantes, o estoque formal de habitações ocorre a partir de $10 \mathrm{~km}$ do centro; por outro lado, o estoque informal de habitações concentra-se entre 5 e 10 km do centro, reflexo da opção pela informalidade para redução dos custos. Em Brasília, 60\% da oferta de habitações formais ocorreu a mais de $20 \mathrm{~km}$ do centro. E menos de $20 \%$ da oferta formal foi a menos de $10 \mathrm{~km}$ do centro.
Ainda mais distinto é o estoque de habitações informais, apesar dos riscos; quem busca uma habitação informal o faz para reduzir principalmente os custos de localização, transporte e acessibilidade. Em Recife e Curitiba, por exemplo, cerca de $40 \%$ do estoque de habitações informais está localizado entre 5 a $10 \mathrm{~km}$ do centro. Em Brasília, 20\% do estoque de habitações informais está a mais de $30 \mathrm{~km}$ do centro. E praticamente não existe a possibilidade de ocupação informal a $10 \mathrm{~km}$ do centro (Dowall e Monkkonen, 2007). Há alguns casos pontuais e particulares, por exemplo na Vila Planalto, ${ }^{5}$ onde a insegurança em relação à propriedade tem levado os moradores parcelarem seus lotes contra o permitido, ou no próprio Plano-Piloto com novas construções ultrapassando a altura máxima permitida.

Todas essas particularidades vão sendo somadas ao preço por metro quadrado, resultando num dos maiores do país. Ainda que justificado em parte devido à alta renda da população brasiliense, o planejamento e o controle governamental do mercado de terras em Brasília contribuem profundamente para 0 alto custo da habitação.

\section{Formação da bolha imobiliária em Brasília}

Analisando o controle sobre os preços da terra e pressupondo que o Governo de Brasília utilizou o instrumento de propriedade do solo de forma eficaz, era de se esperar dois comportamentos alternativos. Uma alternativa seria se o governo tivesse assumido uma postura mais condizente com a função social do 
solo, oferecendo terrenos à população a preços inferiores ao praticado no mercado. Mas se os preços valorizassem além do observado em outras cidades, provaria que o comportamento monopolista do governo é semelhante ao comportamento de mercado, o que é injusto socialmente.

Ocorre que existem recentes indícios da formação de uma Bolha Imobiliária em Brasília. Entende-se por bolha imobiliária o deslocamento entre o preço real do imóvel e o retorno garantido pelo mesmo (FRBSF Economic Letter, 2004). Ou seja, se o retorno de um investimento é pequeno, apesar de continuar atraindo compradores que acreditam que o negócio seja mais rentável do que é na realidade, consequentemente mantida a crença de contínua valorização, a demanda aumenta, contribuindo para manter os preços altos.

Em 2010, estudos feitos pela Universidade Católica de Brasília (UCB) evidenciavam indícios da formação de uma de uma bolha especulativa no Distrito Federal (UCB - Depto. de Economia). Em 2011, estudos feitos pela empresa de consultoria Odds\&Actions, demonstram estatisticamente que já ocorria uma bolha imobiliária na região (Odss\&Actions, 2011).

Tanto o estudo do departamento de economia da UCB como o da consultoria Odds\&Actions dão evidências claras de que há um deslocamento entre o que se paga por um imóvel e a renda obtida com aluguel. Demonstram que os preços elevados dos imóveis locais não garantem um retorno alto para o investimento local. Mesmo assim existem pessoas que continuam optando por esse tipo de investimento devido à expectativa de valorização futura sinalizando a possível ocorrência de bolha especulativa no mercado imobiliário da Capital (Odds\&Actions, 2011).

Em Brasília, o preço por metro quadrado do solo urbano é um dos mais altos do país, ${ }^{6}$ atingindo em média $\mathrm{R} \$ 8.318 / \mathrm{m}^{2}$ no mês de abril de 2013, o maior valor na cidade chega a R\$13.000 na Vila Planalto (mesmo com a insegurança fundiária, com lotes que não têm a escritura definitiva). No Rio de Janeiro, o bairro mais valorizado era o Leblon por $\mathrm{R} \$ 22 \mathrm{mil}$, e na capital paulistana a Vila Nova Conceição por $\mathrm{R} \$ 13$ mil.

Conforme dados do índice "FIPE ZAP de Preços de Imóveis Anunciados", 7 de agosto de 2010 a agosto de 2013 os preços anunciados dos imóveis à venda no Distrito Federal valorizaram 30,8\%, enquanto o Índice de Preços ao Consumidor Ampliado (IPCA) no mesmo período foi de apenas 19,7\%, um spread (diferença entre taxas) de 65\%. 0 IPCA-habitação foi de $17,6 \%$, e também no mesmo período. A taxa de crescimento foi menor do que no Rio e São Paulo, mas como o valor médio atualmente é similar, podemos entender o quanto os preços estavam sobrevalorizados.

São vários os motivos dessa sobrevalorização, dentre os quais, é possível destacar: a alta renda média familiar, a relativa estabilidade do emprego público, espaços reduzidos para a construção civil próximo ao Plano-Piloto (região que concentra boa parte das atividades, dos empregos e dos serviços públicos como saúde e educação).

Tal situação não é diferente nas cidades satélites que refletem a valorização ocorrida no Plano-Piloto. Com a escassez de terrenos livres na região central, as incorporadoras imobiliárias incentivadas pelo programa do governo federal "Minha Casa, Minha Vida" 
descobriram um nicho próspero em cidades como Samambaia, Ceilândia e Taguatinga, além das cidades do entorno como Valparaíso, Novo Gama e Águas Lindas, em Goiás (Navarro, 2009).

Outra evidência da existência de uma bolha imobiliária no Distrito Federal pode ser vista através do aumento dos domicílios vagos, ou seja, unidades que se encontravam efetivamente desocupadas na data de referência do censo demográfico feito pelo IBGE (Diniz e Cavenaghi, 2006, p. 272). Em 2007 eram 40.470 domicílios vagos, um vertiginoso aumento de $52 \%$ em apenas um ano (Fundação João Pinheiro, 2006, p. 25), e suficiente para cobrir $38 \%$ do déficit habitacional à época 107.248 unidades domiciliares, último dado encontrado (ibid., 2009, p. 31). Comparando o percentual de domicílios vagos em relação ao total de domicílios particulares permanentes, no DF esta relação é de $14,6 \%$, acima da média nacional de 11,1\%. 0 Censo de 2010 mostra que havia 62.708 domicílios particulares não-ocupados.

A aparente contradição entre a existência de déficit de moradias ao lado de um enorme número de imóveis sem serem habitados se constitui sempre numa fonte de questionamento. Segundo a Pesquisa Nacional por Amostragem de Domicílios (PNAD), em 2007 mais de $84 \%$ das unidades vagas no país tinham condições de serem ocupadas. Em todo o Brasil, são cerca de 7,351 milhões de imóveis não ocupados, muito mais que suficiente para cobrir o déficit de moradias calculado em 6,273 milhões de imóveis (Fundação João Pinheiro, 2009, p. 44).

\section{Capacidade institucional nas Cidades do Entorno brasiliense}

0 enfrentamento do déficit habitacional não pode ficar a cargo do livre mercado, a exemplo do ocorrido nos Estados Unidos em 2008, pois com a demanda aquecida e a oferta restrita, não apenas os investimentos tornar-se-ão insustentáveis com a especulação desenfreada, 0 alto custo das moradias consequentemente fará com que a população de mais baixa renda, principalmente os que residem em moradias alugadas, sejam deslocadas para regiões cada vez mais distantes de suas atividades diárias cotidianas, tais como o emprego, acesso a serviços públicos de saúde, educação, entre outros equipamentos e serviços públicos, impondo a esses um custo de deslocamento (aí incluso o tempo que também é dinheiro) aumentando ainda mais as desigualdades sociais.

Eis uma contradição importante: enquanto atribui-se que o rigor do ordenamento territorial no Distrito Federal é um dos causadores da segregação espacial e socioeconômica da população. Nas cidades periféricas do entorno da capital, a baixa capacidade administrativa institucional dos governos locais, isto é a baixa capacidade de executar uma política habitacional adequada (Arretche et al., 2012), sujeita a população dessas cidades a sobreviver em regiões sem uma base econômica capaz de gerar emprego, renda, produção e consequentemente, arrecadação de impostos suficiente para atender adequadamente as demandas sociais. 
A hipótese de que o rigor do ordenamento territorial causa segregação é discutível. Será que com a flexibilização desse rigor, haveria menos segregação? Esse argumento é muito utilizado pelos grandes empreendedores imobiliários da região. Em cidades tradicionais há menos segregação? Ao menos em Curitiba e Recife parece que sim (Dowall e Monkkonen, 2007).

A baixa arrecadação de impostos se traduz na elevada dependência de transferência de recursos do Estado e da União através do Fundo de Participação dos Municípios (FPM). Na Região de Desenvolvimento Integrado do Distrito Federal (RIDE-DF), em média essas Transferências Governamentais representam cerca de $75 \%$ do orçamento desses municípios, bem acima da relação encontrada em outras RMs, em torno de $50 \%$.

Uma maior dependência das transferências intergovernamentais implica maior vinculação do orçamento em gastos previstos em lei. No entanto, maiores gastos não significam que as demandas sociais serão melhor atendidas. Eficiência, eficácia e, obviamente, a efetividade das políticas públicas estão intrinsecamente ligadas às capacidades institucionais administrativas desses governos.

Um breve exame dos indicadores dessas capacidades através da Pesquisa de Informações Básicas Municipais em 2008 (IBGE, 2008) mostra que há muito a avançar na região, principalmente quanto à existência de instrumentos de gestão e planejamento do uso do solo urbano. De acordo com esta pesquisa, das cidades que compões a RIDE-DF, somente em $22 \%$ dessas foi verificada a existência de "Conselho Municipal de política urbana, desenvolvimento urbano, da cidade ou similar". 75\% dos municípios não tinham "Plano municipal de habitação". Apenas 55\% tinham "Fundo municipal de habitação" e menos de $27 \%$ tinham "legislação específica" ou "programa de regularização fundiária".

A dependência dos recursos de transferências da União poderia ser reduzida se as cidades explorassem melhor sua base de arrecadação tributária. De acordo com o questionário enviado às prefeituras pelo IBGE, menos da metade cobrava taxa de limpeza urbana, coleta de lixo ou de iluminação pública. Menos de $40 \%$ não tinham qualquer tipo de Política de apoio ao primeiro emprego de jovens e adolescentes (IBGE, 2008). Não é à toa que a região está ultimamente tão violenta, as taxas de homicídio são alarmantes, principalmente entre os jovens. Fala-se em taxas comparadas a de países em guerra (Waiselfisz, 2011).

\section{Re-conhecendo Brasília}

Brasília proporcionou a confusão do entendimento dos limites entre público e privado. O DNA do Plano-Piloto, os pilotis, a ideia, o plano, o conceito da cidade. 0 conceito de propriedade sobre algo material em contraste à propriedade sobre uma projeção. Possuir o real ou o imaginário? Propriedade individual versus coletiva.

A privacidade, privação da cidade, a vida reservada, oculta, foi exposta, escancarada pelas janelas da sala de estar. A Capital tem uma arquitetura panóptica que invoca o mesmo medo difuso apontado pelo sociólogo José Martins (2008). ${ }^{8}$ Um controle social através do medo de ser visto e percebido em desacordo 
com os rígidos costumes sociais requeridos por um modo de vida que pretende ser nobre.

A sala de estar misturou-se ao quintal comum de todas as casas, integrando a residência às praças, aos bulevares entre os blocos residenciais. 0 privado foi transformado em público. A arquitetura panóptica reduz a privacidade do lar, permite 0 acesso visual de quem está do lado de fora da residência.

A mesma ideia privou os cidadãos do que é público, a falta de limites físicos combinada com a ordem, a institucionalidade, a homogeneidade, impediu a vida cotidiana, as trocas das relações humanas, os encontros e desencontros.

Em Brasília, as distâncias são tão grandes que para se locomover é preciso ser transportado. ${ }^{9} 0$ movimento apenas de coisas, as pessoas paradas. Apesar de tanto, não há espaço para o pedestre. É um lugar onde não há mais nem dentro e nem fora. 0 enclausurado é prisioneiro de nada, um engodo (Mongin, 2009, p. 244).

Os condomínios reúnem a elite hermética brasiliense. São a atualização contemporânea dos feudos, das Sesmarias, sem a figura do Senhor, sem um dono, um nobre. Eis a condição do ser urbano brasiliense. Condição de experimentar a obra de urbanistas utópicos. A origem do termo utopia vem do grego óu (não) e topos (lugar), literalmente significa "não-lugar".

Projeto de urbanistas que acreditavam que poderiam construir uma nova sociedade a partir de um novo modelo de cidade. A interação dos homens nessa nova forma construída faria surgir uma nova sociedade. Fez, sim, a cidade do medo. Habitada por medrosos, aprisionados em condomínios. Contraditório, em tempos de prevalência dos fluxos sobre os locais
(Mongin, 2009, p. 131), os condomínios são refúgios que impedem a circulação. Refugiam-se da cidade, do urbano, negam-se a cidade, as ruas.

A proliferação de condomínios não é um privilégio de Brasília, é generalizado nas grandes cidades brasileiras. Somente recentemente a maior rede de condomínios do Brasil, Condomínios Alphaville, começa a empreender em Brasília. A inserção tardia pode ser devida à alta concorrência. Pois mais do que em qualquer outro lugar, a população brasiliense se refugia em condomínios. É irônico o nome da marca. Alphaville é o nome de uma cidade de outra galáxia do filme de Jean-Luc Godard rodado em 1965, na qual um supercomputador comanda de forma cruel e arbitrária uma sociedade técnica completamente alienada e sem sentimentos.

Um outro exemplo de como o poder dos empresários locais do mercado imobiliário impede a concorrência de outros investidores ${ }^{10}$ poder ser percebido verificando 0 número de observações por local do "Índice Fipe-ZAP de preço dos lançamentos imobiliários". É uma questão metodológica da estatística, quanto maior o número de observações, mais representativo é o resultado para a realidade. Enquanto em outras capitais 0 número de observações do índice é da ordem de dezenas de milhares de observações, em Brasília não alcança mil observações. ${ }^{11}$ Para construir esse índice, a Fipe-USP necessita da participação voluntária dos empresários imobiliários, disponibilizando as informações necessárias. Logo percebe-se que não há interesse dos empresários locais de trabalhar em um mercado literalmente livre e aberto, de concorrência perfeita. É o tipo de estratégia 
de empresários que buscam incrementar o lucro através de falhas de informação do mercado. 0 protecionismo geralmente está ligado a algum tipo de atraso da empresa, que reduz a sua capacidade de concorrer no mercado competitivo.

Se toda venda legal de um imóvel tem registro em órgão público, por que ainda não temos uma base de dados pública sobre esse mercado? A resposta é óbvia, não há interesse, nem dos empresários, nem dos governantes. Contrários aos interesses da sociedade.

\section{Brasília, cidade do automóvel ou das carroças?}

A análise dos padrões de consumo da população é uma das formas de indicar a ocorrência de gentrificação. É indício de enobrecimento, o consumo de ostentação, de supérfluos, de produtos de luxo, do chique, do cult dos excessos, do rococó, do barroco.

Constata-se que no Distrito Federal a proporção de carros para uso profissional ou uso fora de estrada ${ }^{12}$ por habitantes, ${ }^{13}$ isto é, carros para uso na roça, ${ }^{14}$ está acima da média nacional, sendo equivalente a estados com economia baseada no setor primário, isto é, extrativismo e agropecuária. (Ver Tabela 1).

Lê-se: $46 \%$ da população do DF possui automóvel, ou, praticamente um carro para cada dois habitantes.

Esse tipo de veículo foi elevado ao status de bens de consumo de luxo. E, contraditoriamente numa cidade político-administrativa, planejada plana, com vias perfeitas para carros de pequeno porte, era de se esperar uma grande quantidade de carros de alta velocidade, pequenos, leves, rentes ao solo. No entanto, em Brasília a quantidade de automóveis de uso profissional ou fora de estrada circulando na cidade está acima da média nacional.

Com essa atitude, a velha elite brasileira demonstra sua riqueza trazendo o rural para o urbano. Uma das vitórias do rural sobre o urbano, da aristocracia sobre a democracia. A paixão por trazer a vida do campo para o urbano. Não é aquele rural caipira, mas um rural de ostentação. A opção por fazer uma cidade para promover o uso do automóvel fica explícita na atual proporção de veículos por habitantes, praticamente um veículo para cada dois habitantes.

Quanto ao custo social, quanto custou Brasília? É um mistério, ninguém sabe com exatidão. Não houve projeto econômico-financeiro, muito menos estudos preliminares ou avaliação de custos e benefícios. Nenhum estudo de viabilidade. Um estudo convencional dificilmente concluiria pela viabilidade, não apenas financeira, mas também física. Construída às pressas, causou graves prejuízos à economia do país. Eugênio Gudin (1969, p. 363) posteriormente fez uma estimativa: 1,5 bilhão de dólares. Em valores atuais, aplicando-se apenas a correção monetária americana, alcançaria 19,5 bilhões de dólares, somando-se juros de $3 \%$ ao ano, padrão médio de taxação, chega-se então a 83 bilhões de dólares.

Isso significa, nos tempos atuais, mais de cinco vezes o custo oficial anunciado das obras para a Copa 2014 (último grande projeto governamental para promover o desenvolvimento urbano). Isso é gentrificação. Utilizar a cultura, a paixão nacional pelo futebol, para promover obras urbanas. 
Tabela 1 - Proporção de veículos automotores por habitantes (\%)

\begin{tabular}{l|c|c}
\hline \multirow{2}{*}{ Taxa de veículos por habitantes } & \multicolumn{2}{|c}{ Característica de uso } \\
\cline { 2 - 3 } & Automóvel de passeio & Profissionais e fora de estrada \\
\hline Brasil & 22,87 & 4,06 \\
Distrito Federal & 41,21 & 5,98 \\
Mato Grosso & 16,90 & 5,77 \\
Mato Grosso do Sul & 22,50 & 5,62 \\
Goiás & 23,89 & 5,57 \\
Paraná & 34,32 & 6,22 \\
Rondônia & 12,91 & 4,52 \\
Minas Gerais & 24,05 & 4,38 \\
Santa Catarina & 37,21 & 6,13 \\
Rio Grande do Sul & 32,24 & 5,13 \\
Espírito Santo & 21,56 & 4,87 \\
São Paulo & 36,77 & 5,68 \\
Roraima & 11,30 & 4,60 \\
Tocantins & 10,79 & 3,80 \\
Acre & 8,74 & 2,94 \\
Amapá & 9,22 & 2,83 \\
Amazonas & 8,98 & 2,61 \\
Bahia & 9,62 & 2,26 \\
Rio Grande do Norte & 12,89 & 2,58 \\
Sergipe & 12,13 & 1,94 \\
Piauí & 7,51 & 2,28 \\
\hline
\end{tabular}

Fonte: Departamento Nacional de Trânsito e Censo populacional-IBGE. Dados de 2010. Elaboração própria.

A legislação urbanística rígida, associada ao tombamento da capital federal, é mais um fator que contribui para especulação imobiliária. Além da escassez de oferta imobiliária intencional, o título de Patrimônio Cultural da Humanidade combinado com o tombamento legal restringe as possibilidades do livre crescimento. Esse é o argumento mais utilizado por grandes empreendedores imobiliários, pedindo flexibilizações para ampliar a oferta imobiliária. Quando isso ocorreu, por exemplo, nos bairros do Sudoeste e o novíssimo Noroeste, a oferta imobiliária não foi para os que mais precisam, foi para as classes de média e alta renda.
Não está sendo defendido que se deve acabar com toda a regulação, com o título de patrimônio, com a preservação da obra Lúcio Costa e Niemeyer. 0 fato é que o Plano-Piloto está sendo descaracterizado. Por grandes e poucos empresários com poder e influência política.

Quem sabe se um dia não fosse exigida a assinatura de um arquiteto, de um engenheiro, de um advogado, de um ambientalista (por pouco não se exige também o aval formal de um economista para verificar a viabilidade financeira) e se a anarquia e o caos fossem possíveis, todos poderiam autoconstruir suas 
habitações. Se a anarquia e o caos um dia fosse possível, quem sabe todos pudessem autoconstruir suas habitações. Sim, a favelização pode ser a solução para as cidades. 0 problema habitacional não é de escassez de terra, é de propriedade.

Brasília ultrapassou os objetivos iniciais e cada vez mais pode ser considerada uma metrópole, inclusive global. Além da óbvia influência nas regiões mais próximas, por sua própria função as decisões tomadas têm impacto por todo o território.

Tem uma arquitetura que atrai turistas de todo o mundo, que muitas vezem vêm visitar apenas as obras faraônicas, não dando a menor importância para a vida social local. Exemplos dessa arquitetura é uma Biblioteca Nacional sem livros, um Museu Nacional ser acervo.

Um estádio nacional sem time e sem torcida. Para ter ocupação na reinauguração em 2013 foi preciso importar dois times de outros estados, Santos-SP e Flamengo-RJ. Pode-se argumentar que fazia parte também da abertura do Campeonato Brasileiro, e Brasília é a Capital do País. Mas é a capital político-administrativa, está longe de ser a capital do futebol, da cultura, da economia. Promoção da imagem da cidade através de eventos esportivos e culturais é um dos principais componentes da gentrificação.

0 trabalho disponível é composto preponderantemente pelas funções quaternárias, político e administrativas, característica das metrópoles globais (Santos, 2008). Passam temporariamente pela capital um rebanho de uma população de transumantes (Cepollaro, 1999), que por curtos períodos vem para trabaIhar em cargos políticos em ministérios, embaixadas, organismos internacionais, centros de pesquisa, universidade e organizações não governamentais. Carregado de preconceito, para Celso Furtado são pessoas que vão para trabaIhar no governo com objetivos muito limitados e específicos, sem viver a cidade. Passa-se um tempo em Brasília e depois deixam a cidade (Couto, 2002, p. 220).

Mas muitos ficaram em Brasília, na realidade mais de dois milhões de pessoas escolheram morar na capital, atraídos pela promessa de uma qualidade de vida superior ou igual às melhores cidades brasileiras. Já os turistas que escolhem visitar Brasília não vêm para conhecer os candangos, visitando as Cidades Satélites. Em uma pesquisa de satisfação realizada pela Centro de Excelência em Turismo da Universidade de Brasília (CET-UnB), 65\% dos entrevistados não manifestaram interesses em visitar as Cidades Satélites. Menos ainda para fazer negócios nessas áreas, pois 73\% declaram não ter interesse de visitar nenhuma dessas cidades (CET-UnB/BrasiliaTur, 2008).

\section{Consideraç̧ões finais}

A compreensão do processo de gentrificação mostra que o problema engloba muito mais do que a valorização imobiliária de uma localidade, vai além dos efeitos sobre a população afetada, geralmente a de menor renda, em um processo considerado "normal", é deslocada das áreas valorizadas.

A gentrificação, quando percebida no mercado imobiliário, já é parte de um amplo processo generalizado, resultado da interação de políticas públicas direcionadas ao incremento da arrecadação, via promoção da reprodução 
da acumulação de capital, excludente. Parte intrínseca de um modelo de desenvolvimento nacional baseado na expansão da acumulação do capital. São várias escalas, casos locais resultados de articulações globais, evidenciando que as relações externas muitas vezes prevalecem em importância e influência sobre as relações do contexto local.

Uma das características da gentrificação está relacionada às garantias da segurança da reprodução do capital. Nos tempos de colônia, com a permissão legal da escravidão, a coação ao trabalho era feita pelo medo do castigo físico. Foi encontrada nas origens da formação do subúrbio paulistano, na Vila de Paranapiacaba, a transformação deste modus operandi. A arquitetura da vila substituiu o medo da chibata por um medo difuso. Houve a interiorização não mais do medo físico, mas agora, da coação psicológica do operário (Martins, 2008, p. 30). Uma disciplina das relações de trabalho e sociais baseada menos na racionalidade do contrato e mais no medo. As pessoas devem ter medo para que se cumpra a funcionalidade da sociedade moderna, para que a ficção da igualdade jurídica cumpra suas funções imaginárias. É assim que a sociedade funciona até hoje.

0 exemplo maior é Brasília, com sua arquitetura panóptica invoca o mesmo medo difuso apontado pelo sociólogo citado. Um controle social pelo medo de ser visto e percebido em desacordo com os rígidos costumes sociais requeridos por um modo de vida que pretende ser nobre.

A forma das cidades é composta por vias de duas mãos. A forma simultaneamente reflete e condiciona a reprodução do capital. A metrópole, cria da revolução industrial, representa a extensão do domínio do sistema-fábrica para a organização do espaço (Cepollaro, 1999). As profundas transformações na percepção da relação entre tempo e espaço não afetaram apenas os conteúdos materiais, os fluxos de transporte e comunicação. Afetaram importantes aspectos das relações sociais, das atividades dos movimentos humanos.

Brasília é a concretização do peabiru brasileiro. 0 caminho de desenvolvimento do litoral para o interior. Concreto e asfalto sobre 0 caminho de grama pisada. A construção da Capital Federal está em um processo que levou as cidades a se alinharem à disciplina e lógica do desenvolvimento capitalista. É o local de diversas contradições e inversão de valores. Primeiro se fizeram as estradas, depois as avenidas, as ruas, os blocos residenciais. Foram pensadas mais para a promoção do automóvel do que para as pessoas. Mais para o motor do modelo de desenvolvimento nacional e menos para o conjunto da sociedade. 0 fato é que na capital primeiro se fizeram as ruas para os veículos, recentemente as ciclovias, mas ainda faltam calçadas para os pedestres.

Associar a Brasília o entendimento de Otília Arantes (2000, p. 31) de que uma cidade inteiramente planejada é uma cidade inteiramente gentrificada é um exagero, mas com ressalvas, não é proibitivo de ser feito. Brasília não foi inteiramente planejada, teve um Plano-Piloto, um projeto inicial, e a partir dele, a cidade seguiu seu caminho natural. Um caminho distinto, devido às suas particularidades locais, determinadas em função dos interesses nacionais. Os mesmos problemas urbanos nacionais aparecem intensificados devido às características singulares locais.

O Distrito Federal e Cidades do Entorno, a região metropolitana brasiliense, expressam 
a síntese do nacional. E como síntese dos problemas urbanos, sua expressão e efeitos são mais intensos. Originalmente apesar do plano conter a ideia de integração entre classes sociais pelo uso comum de escolas, comércio e clubes, na prática, famílias de classes sociais diferentes foram morar em localidades diferentes. Os pobres distantes do centro de empregos e serviços públicos.

0 monopólio da propriedade de terras em poder público que poderia ter servido para melhor distribuir o acesso à moradia, na contramão do esperado, tem servido aos interesses dos grandes empresários imobiliários.

A alta carga de regulação urbanística e intervencionismo estatal, defendida sob argumentos de preservação arquitetônica e ambiental, contribui profundamente para a especulação imobiliária. A formação do subúrbio brasiliense é resultado da falta de capacidade do poder público local em atender à crescente demanda por moradia. É assim em todo o país. Mas as restrições impostas, principalmente na área protegida, obrigaram a população a buscar alternativas. Os de maior renda refugiaram-se nos condomínios irregulares. Os de menor renda foram expulsos das invasões ilegais.

A especulação imobiliária na Capital é percebida através da formação de uma bolha imobiliária, isto é, o descolamento dos preços imobiliários em relação à realidade social. Em Brasília, encontra-se um dos mais altos preços por metro quadrado do solo urbano no país. Mas há profunda diferença entre morar num amplo apartamento no Leblon-RJ com vista para o mar, ou na Vila Nova Conceição-SP ao lado do parque do Ibirapuera, comparado a morar nos apartamentos do Plano-Piloto.
0 enfrentamento do déficit habitacional não pode ficar a cargo do livre mercado, muito menos de um poder público orientado pelo mercado. No subúrbio brasiliense, nas Cidades do Entorno transparece uma contradição relacionada ao grau de intervenção do estado. Nesses municípios, ao contrário da Capital, verificou-se que há baixa capacidade institucional para implementar e executar uma política habitacional adequada. Esse fato, associado à baixa capacidade de geração de fontes de renda própria, isto é, de geração de impostos, corroborada pela baixa participação das receitas tributárias na composição da receita orçamentária desses municípios, limita os investimentos dos governos locais necessários para as obras urbanas demandadas.

A ironia das contradições da condição urbana brasiliense é expressa nos padrões de consumo. A forma de expressão da gentrificação generalizada que transpassa o mercado imobiliário. Um padrão de consumo que prova o quanto o jargão é verdadeiro, de que Brasília é a cidade do e para o automóvel. A proporção de carros por habitantes é a maior, isto é, é o dobro da média nacional. 0 mais irônico é em uma localidade urbana a proporção de veículos para uso rural e de uso profissional, ser maior do que em estados com economia predominante rural.

A proliferação do modo de vida refugiado em condomínios irregulares, ou vivendo em cidades distantes em invasões ilegais, demonstra um amplo processo generalizado de gentrificação. Com particularidades locais, mas condicionado ao amplo processo de reprodução do capital.

0 problema do déficit habitacional não é de escassez de solo, é de propriedade. Não 
é somente uma escassez material, é de caráter de regulação das relações sociais.

A solução encontrada nas favelas, apesar de todas as problemáticas ali presentes, por outro lado revela a capacidade dos habitantes de se organizarem e "fazerem a cidade", uma cooperativa de fazer a cidade. A experiência mostra que para obter soluções eficazes para os problemas urbanos a participação da população afetada é de suma importância.

Devemos reconhecer que não é possível ter uma resposta, um modelo de solução única. 0 problema é estrutural, e por isso as soluções não podem ser conjunturais, de curto prazo, soluções de governo. São necessárias soluções de Estado.

0 direito à cidade não se resume ao direito de visitar, de ser espectador da produção da cidade; esse direito deve reconhecer nos habitantes a capacidade de construir efetivamente a cidade, o direito de serem agentes ativos. As políticas públicas não podem se limitar a considerar que os deslocamentos urbanos sejam apenas relacionados ao trabalho, pois a vida do trabalhador não se resume a apenas trabalhar (por mais que isso esteja se tornando uma verdade absoluta). A vida do trabalhador não teria sentido não fossem as coisas sem sentido que fazemos enquanto não estamos trabalhando.

Da gentry inglesa, aburguesada pela indústria... 0 primeiro teórico do urbanismo, Ildefons Cerdà escrevia em 1867:

Vou iniciar o leitor no estudo de uma maneira completamente nova, intacta e virgem. Como tudo ali era novo foi preciso que eu buscasse e inventasse palavras novas para exprimir ideias novas cuja explicação não se encontra em nenhum léxico. ${ }^{15}$

Muito mudou depois disso e por isso foi preciso reencontrar o sentido de algumas palavras. Gentrificar: tornar nobre. As ideias fora do lugar, no lugar fora das ideias. Brasília, Cidade COM-FUSA. Cidade das CAR-ROÇAS. Lugar que priva da cidade. A pá lavra. 0 trabalho gentrifica o homem.

\section{William Lauriano}

Universidade de Brasíla, Departamento de Arquitetura e Urbanismo. Brasília/DF, Brasil. laurianow@yahoo.com.br 


\section{Notas}

(1) Lei n. 3.715/1960, artigo 38 (conhecida por Lei Santiago Dantas) determina que "qualquer alteração no Plano-Piloto a que obedece a urbanização de Brasília depende de autorização de lei federal".

(2) Com menor intensidade.

(3) Através do Banco de Brasília (BRB) e da Terracap.

(4) Essa é a raridade. Uma empresa imobiliária pública com participação do $50 \%$ do Governo Federal e $50 \%$ do Governo do Distrito Federal.

(5) A Vila Planalto tem origem do que sobrou dos acampamentos de operários que não foram removidos ao final da construção. Resistiram até que em 21 de abril de 1988, foi tombada Patrimônio Histórico do Distrito Federal. Em 2013, foi elevada ao status de Cidade Satélite, isto é, uma região administrativa com Administrador próprio (mas escolhido pelo governador). Até 2013, a propriedade dos lotes ainda é indefinida. Foi concedido aos "pioneiros" (trabalhadores que participaram da construção) o direito de uso dos lotes.

(6) Ver anexo II: Cálculo da rentabilidade do imóvel e formação da bolha imobiliária.

(6) Alternando a liderança no ranking com Rio de Janeiro e São Paulo.

(7) O índice Fipe ZAP de Preços de Imóveis Anunciados é o indicador de preços de imóveis é produzido em parceria entre a Fipe-USP e a empresa de classificados ZAP Imóveis. É considerado o principal termômetro do mercado imobiliário brasileiro.

(8) Em A aparição do demônio na fábrica..., José de Souza Martins verifica a importância da construção da ferrovia Santos-Jundiaí nas transformações sociais, a saber a percepção entre tempo e espaço. Verificou que o plano de construção e funcionamento da vila operária de Paranapiacaba foi presidido pela ideia de que a disciplina do trabalho dependia da interiorização de temores, sobretudo o temor de ser visto fazendo o que não deveria ser feito. A vila foi baseada na concepção do presídio panóptico, na concepção baseada na interiorização subjetiva do agente de vigilância. O medo através da autorrepressão psicológica. Na vila, tudo podia ser visto a partir da residência do engenheiro-chefe, construída do alto de um morro, permitindo a observação das instalações da ferrovia e das residências dos operários. Imputava a ideia de que a pessoa se sentisse tão visível que nada lhe restava a não ser ter medo dessa visibilidade e suas consequências (Martins, 2008).

(9) E quem pode vai de automóvel particular.

(10) De outros estados ou mesmo investidores internacionais.

(11) 937 observações em agosto de 2013.

(12) São veículos $4 \times 4$, caminhonetes e caminhonetas, conforme classificação do Departamento Nacional de Trânsito.

(13) Automóveis per capita.

(14) CAR-ROÇAS, carros para uso na roça, inspirado em Abramo (2007).

(15) Esta é a introdução da Teoria general de la urbanización de Cerdá (1867). 


\section{Referências}

ABRAMO, P. (2001). Mercado e ordem urbana: do caos à teoria da localização residencial. Rio de Janeiro: FAPERJ.

(2007). A cidade COM-FUSA. A mão inoxidável do mercado e a a produção da estrutura urbana nas grandes metróploes latino-americanas. Revista Brasileira de Estudos Urbanos e Regionais, v. 9, n. 2, pp. 25-54.

ARANTES, O. B. F. (2000). "Uma estratégia fatal”. In: ARANTES, O. et al. A cidade do pensamento único. Petrópolis, Vozes.

ARRETCHE, M. et al. (2012). Capacidades administrativas dos municípios brasileiros para a política habitacional. Brasília: Centro de Estudos da Metrópole-Cebrap. Secretaria Nacional de Habitação, Ministério das Cidades.

BOMENY, H. (s.d.) FGV/CPDOC (Centro de Pesquisa e Documentação de História Contemporânea do Brasil). [Online] Disponível em: http://cpdoc.fgv.br/producao/dossies/JK/artigos/Educacao/ UNB. Acesso em: 21 abr 2013.

CARPINTERO, A. C. C. (2010). “Brasília, patrimônio de quem?”. In: FERNANDES, E. e ALFONSIN, B. Revisitando o instituto de tombamento. Belo Horizonte, Fórum.

CEPOlLARO, G. (1999). “Gottmann: A metrópole transacional”. In: DE MASI, D. A. A sociedade pós-industrial. São Paulo, Senac.

CERDÁ, I. (1867). Teoría general de la urbanización y aplicación de sus principios y doctrinas a la Reforma y Ensanche de Barcelona. Madri, Imprenta Española.

CET-UnB/BrasiliaTur (2008). Pesquisa do perfil e da satisfação do turista de lazer e de negócios em Brasília. Brasília, s.n.

COUTO, R. C. (2002). Brasília Kubitschek de Oliveira. Rio de Janeiro, Record.

DE MASI, D. (1999). A sociedade pós-industrial. São Paulo, Senac.

DINIZ, J. E. e CAVENAGHI, S. (2006). “Déficit habitancional, famílias conviventes e condições de moradia". In: GUIMARÃES, J. R. S. Demografia dos negócios. Campinas, Abep.

DOWALL, D. E. e MONKKONEN, P. (2007). Consequences of the Plano Piloto: The Urban Development and Land Markets of Brasília. Urban Studies, v. 44, pp. 1871-1887.

FARRET, R. (2001). Land and urban developments policies in a planned city: achievements and challenges in Brasília, Brazil. Urban and Reginal Planning in Brazil, v. 37, n. 147, pp. 8-13.

FARRET, R. L. (1985). “O Estado, a questão territorial e as bases de implantação de Brasília”. In: PAVIANI, A. (ed.). Brasíia, ideologia e realidade. São Paulo, Projeto Editores Associados.

FRBSF ECONOMIC LETTER (2004). House prices and fundamental value. s.I.:s.n.

FREYRE, G. D. M. (1968). Brasis, Brasil e Brasília. Rio de Janeiro, Record.

FUNDAÇÃO JOÃO PINHEIRO (2006). Déficit habitacional no Brasil - 2005. Brasília, Ministério das Cidades. (2009). Déficit habitacional no Brasil - 2007. Brasília, Ministério das Cidades. 
GOMIDE, L. e AGUIRRE, L. (2011). Rentabilidade dos Imóveis no Distrito Federal. Brasília, Odds\&Action.

GOVERNO DO DISTRITO FEDERAL - Administração Regional da Ceilândia (2013). www.ceilandia.df.gov. br. [Online]. Disponível em: http://www.ceilandia.df.gov.br/sobre-a-ra-ix/conheca-ceilandia-raix.html Acesso em: 21 abr 2013.

GUDIN, E. (1969). Para um Brasil melhor. Revista Conjuntura Econômica, pp. 362-363-368.

IBGE (2008). Perfil dos municípios Brasileiros. Perfil de informações municipais básicas. Rio de Janeiro, Instituto Brasileiro de Geografia e Estatística.

MARTINS, J. D. S. (2008). A aparição do demônio na fãbrica: orgens sociais do Eu dividido no subúrbio operário. São Paulo, Editora34.

MONGIN, O. (2009). A condição urbana: a cidade na era da globalização. São Paulo, Estação Liberdade.

NAVARRO, L. (2009). Cidades vizinha a Brasília vivem "boom" imobiliário. Correio Brasiliense, 28/6.

ODDS\&ACTIONS (2011). Estudo sobre a Bolha Imobiliária no DF. Avaliação de apartamentos em Brasília e Águas Claras. Brasília: s.n.

SABOIA, L. e SANDOVAL, L. (2012). A cidade é uma só? Luta por reconhecimento na relação centro-periferia em Brasília. In: III SEMINÁRIO INTERNACIONAL URBICENTROS. Anais. Salvador-BA.

SANTOS, M. (2008). A natureza do espaço. São Paulo, Edusp.

SMITH, N. (2006). "A gentrificação generalizada: de uma anomalia local à "regeneração" urbana como estratégia urbana global". In: BIDOU-ZACHARIASEN, C. De volta à cidade: dos processos de gentrificação às políticas de "revitalização" dos centros urbanos. São Paulo, Annablume.

(2007). Gentrificação, a fronteira e a reestruturação do espaço urbano. GEOUSP - Espaço e Tempo, pp. 15-31.

UCB - Departamento de Economia (2011). Carta Econômica - Índice bolha. Janeiro a maio.

WAISELFISZ, J. J. (2011). Mapa da violência 2012. Os novos padrões de violência homicida no Brasil. São Paulo, Instituto Sangari.

Texto recebido em 13/jan/2014

Texto aprovado em 16/out/2014 